\title{
The Countermeasures for Calligraphy Education in Colleges and Universities of Yunnan Province
}

\author{
Yaping Yang ${ }^{1, *}$ \\ ${ }^{1}$ Baoshan University, Baoshan, Yunnan 678000, China \\ *Corresponding author. Email: yangyapingyn@163.com

\begin{abstract}
Chinese calligraphy has a long history, takes Chinese characters as the carrier, and contains profound cultural connotations. Taking calligraphy education in colleges and universities of Yunnan Province as an example, and aiming at the current status of the construction of the teaching staff, the development of disciplines and the cultivation of talents, this article proposes countermeasures from three aspects, such as creating an atmosphere, improving the quality of teachers, and building a calligraphy education system.
\end{abstract}

Keywords: Yunnan, Colleges and universities, Calligraphy education, Countermeasures.

\section{INTRODUCTION}

Chinese calligraphy, which takes Chinese characters as the carrier, is the basis of Chinese civilization and the foundation of Chinese traditional culture. With the popularization of calligraphy education, the calligraphy education in colleges and universities of Yunnan Province has gradually recovered. In view of the difficulties in the construction of teachers, the development of discipline and talent training, the author and members of this subject put forward corresponding countermeasures in combination with the experience of more than 20 years in calligraphy education in colleges and universities.

\section{CREATING AN ATMOSPHERE AND INHERITING CALLIGRAPHY CULTURE}

\subsection{Creating a Good Environment for the Calligraphy Education}

The author thinks that it is necessary to build a good environment for calligraphy education, so as to strengthen the calligraphy education in colleges and universities. Among the 200 questionnaires

*Fund: This article is supported by the project results of the Scientific Research Fund of the Department of Education of Yunnan Province - "Research on Calligraphy Education in Colleges and Universities in Yunnan Province" (project number: 2019J0335). issued by the research group, $64.8 \%$ of the students choose to create a good environment for calligraphy education. According to the data, college students hope that the universities can provide and build a good education environment and platform for them to learn calligraphy. Through regular activities such as calligraphy forum, cultural salon and calligraphy exhibition, students can have a good environment, make mutual exchange, enhance learning motivation and improve cultural literacy and practical ability.

\subsection{Giving Full Play to the Role of College Student Associations}

Taking participation in college student association is an effective way to enrich students' extracurricular life. Through building a platform for mutual communication, the students' specialities can be fully exerted, so that students have the excellent qualities, such as the sense of gain, sense of achievement and sense of being confident. Therefore, how to play a good role of associations is a topic to be discussed, and then more students of different majors and different grades can participate in it.

\subsubsection{Hardware Facilities}

As the instructor of the College Student Painting and Calligraphy Association of Baoshan University, the author has spent more than 20 years. 
At the same time, the author grows up with them. Activity venues include random classrooms in the original normal colleges (old campus) and random terrace classroom in the new campus and reading rooms in the library. At present, relatively fixed classrooms can be used. However, the space for activities is still limited, which does bring inconvenience to students from different majors of this university. It is recommended that the Youth League Committee of various colleges and universities should actively provide help and support, so as to provide suitable fixed places and create a good learning atmosphere for students. Due to the randomness, it will bring a lot of inconvenience to students. The blackboards, multimedia equipment, desks and stools necessary for writing should be provided in the premises.

\subsubsection{Funding Guarantee}

It is suggested that under the reasonable expenditures of university funds, the Youth League Committee of colleges and universities can continue to support university student associations. After all, the monthly membership fees are limited. For example, if the calligraphy exhibitions are carried out among the colleges and universities, the mounting fees will account a lot. In this regard, the universities are particularly required to provide corresponding funding guarantees.

\subsubsection{The Construction of Network Platforms}

The Internet has convenient, powerful, and efficient functions. It is not only a window for shaping the image, but also can enhance online interaction and communication between teachers and students, and between students. Especially with the continued and in-depth development of digital and networked education in the context of the "epidemic", colleges and universities should pay more attention to the construction of the network platform of various college student associations. The network platform can be managed under the supervision of the publicity department, the Youth League Committee and other departments, relying on associations such as the College Student Painting and Calligraphy Association. In the process of platform construction, it is necessary to construct the fields for classic work appreciation, work display, teaching video, teacher-student exchange, Q\&A, etc. With the richness of the website, the number of audiences will increase, and more calligraphy enthusiasts can participate in it.

\subsubsection{Organizing Public Welfare Activities}

Calligraphy is an excellent traditional culture of the Chinese nation. When carrying out all kinds of calligraphy education activities, teachers should correctly guide and encourage students to participate in more public welfare activities of calligraphy, rather than for the purpose of utilitarianism. For example, on the eve of winter vacation, it is suggested to carry out the activity of "writing Spring Festival couplets for free" inside and outside the university. And students who have painting skills can participate in the activity of "constructing beautiful rural areas", and participate in calligraphy and painting practice activities. Also, students with solid foundation can actively participate in the series of activities of calligraphy and painting charity sale organized by the local Red Cross Association. According to various voluntary activities, students can learn to be grateful, learn to care, and bring happiness and artistic enjoyment to others with their own expertise. This not only enriches the second classroom for the students, but also improves their comprehensive quality.

\section{LAYING A SOLID FOUNDATION AND IMPROVING THE QUALITY OF TEACHING STAFF}

Based on the teaching and discipline construction of calligraphy major, it is required to pay attention to the academic theory and calligraphy practice ability in the context of taking high academic level as the standard. This puts forward new requirements for calligraphy educators. In addition to professional ability, they should also have a comprehensive knowledge system. The teachers should not only pay attention to academic exchanges in China and foreign countries, but also expand the channels for acquiring education and teaching resources, in order to broaden their horizons. At the same time, it is suggested to reconstruct the talent training system for students of calligraphy majors and nonprofessional students. Also, it is necessary to cultivate students' self-development awareness and self-development potential, and strive to teach students in accordance with their aptitude. Taking into account scientific research and the improvement of theoretical level, it is required to constantly strengthen literature and art cultivation. And then, people can boldly respond to the challenge of calligraphy education in the new era and shoulder the responsibility of carrying forward the excellent traditional Chinese culture. 


\section{INNOVATING THE MODE AND CONSTRUCTING THE DEVELOPMENT SYSTEM OF CALLIGRAPHY EDUCATION}

\subsection{Calligraphy Major}

Calligraphy is a unique traditional art in China. The Ministry of Education has always attached importance to the cultivation of calligraphy talents. According to the reply letter of No. 3904 proposal (JY 352) of the first meeting of the 13th National Committee of the CPPCC, the university is supported to independently set up the secondary subject or research direction of "calligraphy". According to the "measures for the establishment and administration of academic catalogues for degree awarding and personnel training" promulgated by the degree committee of the State Council and the Ministry of education, the secondary disciplines shall be independently set up by the degree awarding units. In 2018, degree awarding units such as Jinan University and Sichuan University have independently set up the related secondary disciplines such as "calligraphy", "Chinese painting and calligraphy" under the firstclass disciplines such as "fine arts", and carried out personnel training. The newly revised "catalogue of undergraduate majors in general colleges and universities" has been promulgated and implemented. Then, art becomes an independent subject category from literature, and there are 41 undergraduate majors, including drama, performance, drama film and television director, drama film and television art design, which provides important support for promoting higher art education. The documents such as the "regulations on the undergraduate specialty setting in general colleges and universities" and "the catalogue of undergraduate majors in general colleges and universities (2012)" are issued. And there are three categories: discipline category, specialty category and specialty. The system of undergraduate specialty catalogue is established, which is unified, stable and relatively open. Also, the dynamic adjustment mechanism of discipline is established. The compliance between discipline and social demand is obviously improved. The Ministry of Education will continue to provide supports for qualified universities to independently set up the secondary disciplines or research directions of calligraphy under the relevant first-class disciplines such as "fine arts", and cultivate high-level talents with doctoral and master's degree. According to the results of the filing and approval of undergraduate majors (calligraphy) in general colleges and universities in 2020 by the Ministry of Education, there are currently eight colleges and universities in Yunnan Province setting up calligraphy major. Among them, calligraphy major of Yuxi Normal University is included in the list of newly added majors in the undergraduate specialty catalogue of general colleges and universities in 2021. This is a good start, will continue to promote the development and construction of calligraphy discipline in Yunnan Province, guide colleges and universities to further optimize the talent training system, and constantly improve the structure and connotation of calligraphy discipline.

In view of the development of calligraphy major in colleges and universities of Yunnan Province, whether it is for the construction of professional courses or professional elective courses, it is necessary to pay attention to local cultural resources, give full play to the role of famous scholars, steles and posts in Yunnan Province, strengthen cultural confidence and focus on development. More importantly, colleges and universities should take measures in accordance with the nature of their own schools, characteristics of running schools and personnel training objectives and positioning. While taking into account the cultivation of academic accomplishment, theoretical knowledge, basic skills and creative personality, normal colleges and universities can give priority to training calligraphy education talents, and cultivate them to have the preliminary research ability, creative ability and teaching ability of calligraphy education and teaching. The comprehensive colleges and universities and art universities can move towards cultivating high-level calligraphy talents. Therefore, for the calligraphy education and academic theory in colleges and universities of Yunnan Province, it is necessary to form a talent training pattern of "a hundred flowers bloom and a hundred schools of thought contend", rather than a cookie-cutter training model, in order to meet the society's demand for calligraphy talents in many aspects.

At the same time, colleges and universities should take into account the development of calligraphy practice activities, and rely on various art forms to strengthen the construction of the second classroom, so as to achieve an effective connection between the two classrooms. Relying on the resources of local culture, ethnic minority calligraphy, stele inscriptions, etc. in Yunnan 
Province, professional development courses can be carried out among teaching and research offices, league associations, and societies. By allowing students to personally feel the charm of calligraphy in local culture, students can consciously cultivate their aesthetic sentiment and enhance the artistic taste, which will play a positive role in building good calligraphy culture in colleges and universities. For example, in the process of enriching academic and theoretical research, teachers and students can give full play to professional advantages and develop calligraphy creations that reflect local history and culture, express regional and national characteristics, and show local elegance. Students can experience and appreciate beauty in the process of expressing and creating beauty. Also, during this process, it can enlighten the students' minds and cultivate the students' spirits. At the same time, students can feel the charm of culture while exercising their artistic practice ability. Through the development of cultural activities with distinctive characteristics and outstanding professional characteristics, teachers and students are encouraged to participate actively, so as to make the campus culture more humanistic and educating.

Therefore, in view of the current situation of calligraphy education in colleges and universities of Yunnan Province, it is necessary to combine unique regional cultural background of Yunnan Province, develop calligraphy courses, compile calligraphy textbooks with distinctive characteristics, and conduct in-depth research on calligraphy education. It is required to attach importance to the calligraphy of ethnic minorities in Yunnan Province, and formulate effective inheritance and protection measures, build a calligraphy education system with Yunnan characteristics, and vigorously develop the cause of calligraphy.

\subsection{Professional Integration}

The classroom is the most important position for colleges and universities to carry out various education and teaching activities. No matter what kind of courses or professional students a teacher faces, it is a teacher's natural responsibility to do well in each course. Ouyang Zhongshi believes that "calligraphy" should be raised to the level of "calligraphy culture". As an excellent traditional culture of the Chinese nation, it is rooted in the hearts of Chinese people, with the long history and profoundness.
Regardless of whether calligraphy is a required professional course or a public elective course, how to improve the quality of classroom teaching and enhance the motivation of students to learn is a hot topic. Teachers can make full use of the different subject knowledge and content to promote calligraphy teaching, and at the same time, effectively promote students' initiative in learning other subjects.

In the context of "new liberal arts", calligraphy and related disciplines are integrated in teaching, which puts forward higher requirements for calligraphy teachers. The process of learning calligraphy is the process of learning history. The emergence of each type of calligraphy in the brief history of calligraphy is closely related to the historical background of the time. Teachers can analyze the mission of calligraphy in each historical period from the perspective of history. When appreciating and copying classic rubbings, the lines and columns of language and characters are full of humanity. It involves poems, songs, couplets, etc. Teachers can interpret the calligraphy content while teaching calligraphy. It can be said that the process of appreciating and copying is the process of students learning literary knowledge. Virtually, students accumulate a wealth of literary knowledge. At the same time, it is suggested to judge the pros and cons of a calligraphy work from an aesthetic point of view, so that the beautiful text content and the formal beauty of calligraphy can be organically combined. This is reflected in the sixteen-character calligraphy thought of Ouyang Zhongshi, that is, "characters are the carriers of culture, and calligraphy is practical".

Both calligraphy and Chinese painting pay great attention to the theory of "taking white as black" and "leaving the black and keeping the white". These points of view are contained in the structure of the character and in the whole work. According to the contrast between the black brushwork and the white space, the beauty of "harmony" and "neutrality" is ultimately achieved. It is a concentrated expression of the courage and style of calligraphers in the contrast between the black brushwork and the white space. When analyzing the relationship between words, groups and ranks, it is necessary to appreciate the proportion, the weight, the thickness, the straightness and the deficiency of the character, and so on. In order to achieve a harmonious balance of writing, symmetrical transformations are often incorporated into mathematics, and the structure of characters is closely related to different geometric figures. The 
external forms, such as sheets, banners, sketches, etc., also correspond to various figures in geometry. Music pays attention to tonality, rhythm and speed, and calligraphy pays attention to the weight of the brush and the speed of writing. In the music, the sound is broken and the breath is connected. In the calligraphy, the brush is broken but the meaning is connected. The inner qualities of the two coincide. Calligraphy has similarities with design disciplines, such as graphic design, environmental design, advertising posters, packaging design, and arts and crafts. Product design is inseparable from text descriptions, and sometimes computer art characters are not as artistically appealing as personalized handwritten Chinese characters. Teachers give correct guidance to demonstrate the charm of calligraphy culture. Undoubtedly, there is a close relationship between calligraphy and related disciplines. This is a concentrated expression of the social function, education function and aesthetic function of calligraphy. It also allows the comprehensive application of cultural knowledge of various subjects in the process of calligraphy teaching, so as to arouse students' interest in learning calligraphy, guide students to correctly understand the function and value of calligraphy, and cultivate students' artistic perception and innovative spirit.

\section{CONCLUSION}

Calligraphy education in colleges and universities bears the historical responsibility and mission of inheriting and spreading Chinese traditional culture. While paying attention to the cultivation of professional talents, colleges and universities should timely broaden the courses related to calligraphy to expand the audiences. It is suggested to strengthen the teaching of calligraphy, and encourage more qualified teachers to offer elective calligraphy courses. It is required to give full play to the advantages of smart classroom and actively explore the construction of calligraphy MOOCS by school-based and inter-school excellent calligraphy teachers, experts and scholars (colleges and universities inside and outside the province), so as to meet the needs of students to receive calligraphy education through online teaching, and broaden educational resources and ways. It is firmly believed that the calligraphy education in colleges and universities of Yunnan Province will have rich results under the leadership of the "eight" universities that set up calligraphy.

\section{AUTHORS' CONTRIBUTIONS}

This paper is independently completed by Yaping Yang.

\section{REFERENCES}

[1] Ouyang Zhongshi (editor-in-chief). Calligraphy Tutorial, Beijing: Higher Education Press, 2011.8. (in Chinese)

[2] Yang Suoqiang. Dissemination: Yang Suoqiang's Calligraphy Collection, Shaanxi: Xi'an Jiaotong University Press, 2014.10. (in Chinese)

[3] Chen Longhai. College Calligraphy Course, Beijing: Higher Education Press, 2019.10. (in Chinese)

[4] Zeng Chuanguo. College Calligraphy Course, Hunan: Central South University Press, September 2018. (in Chinese)

[5] Cui Wei (editor). Selections of Master's Degree Papers in Calligraphy, Beijing: Rongbaozhai Publishing House, 2010.1. (in Chinese)

[6] Li Zaixiang. Implementation and Popularization of Calligraphy Education. Hunan: Hunan Normal University Press, June 2013. (in Chinese) 